\title{
SPINE SURGERY IN JOS, NIGERIA- AN INITIAL EXPERIENCE
}

\author{
Ode Michael Bundepuun1, Taiwo Femi Olu², Amupitan Idumagbodi³, Onche Icha Inalegwu4 ${ }^{4}$ Ode Gloria Nengi ${ }^{5}, Y_{u s u f ~ N u h u^{6}}$ \\ ${ }^{1}$ Consultant Orthopaedic Surgeon, Department of Orthopaedics and Trauma, Jos University Teaching Hospital/ Daisyland Orthopaedic \\ Hospital, Plateau State, Nigeria. \\ ${ }^{2}$ Consultant Orthopaedic Surgeon, Department of Orthopaedics and Trauma, Jos University Teaching Hospital/ Daisyland Orthopaedic \\ Hospital, Plateau State, Nigeria. \\ ${ }^{3}$ Consultant Orthopaedic Surgeon, Department of Orthopaedics and Trauma, Jos University Teaching Hospital/ Daisyland Orthopaedic \\ Hospital, Plateau State, Nigeria. \\ ${ }^{4}$ Consultant Orthopaedic Surgeon, Department of Orthopaedics and Trauma, Jos University Teaching Hospital/ Daisyland Orthopaedic \\ Hospital, Plateau State, Nigeria. \\ ${ }^{5}$ Community Health Physician, Jos University Teaching Hospital, Plateau State, Nigeria. \\ ${ }^{6}$ Consultant Orthopaedic Surgeon, Department of Orthopaedics and Trauma, Barau Dikko Teaching Hospital, Kaduna, Nigeria.
}

\section{ABSTRACT}

\section{BACKGROUND}

Spine pathologies are a common presentation to Orthopaedicians and Neurosurgeons and include degenerative diseases of the spine, spine tumours, traumatic spine injuries, spine infections and spine deformities. Non-operative and operative treatment modalities are employed in the treatment of these conditions. The increasing ageing population worldwide has resulted in an increase in the degenerative spine conditions presenting to the clinician. Many surgical procedures are employed in the treatment of these conditions.

The aim of this study was to evaluate the procedures carried out and attendant outcomes.

\section{MATERIALS AND METHODS}

This was a case series of spine surgeries carried out over a 2-year period (2015 to 2017) in hospitals in Jos Nigeria. The data was reviewed retrospectively. They were analysed for spine pathologies; operative procedures were carried out. Duration of procedures, outcomes and complications were observed. The outcome was assessed using numeric pain scale. Data was analysed using the Epi Info statistical software.

\section{RESULTS}

25 patients in total were operated within the said period. Ages ranged between 35 and 77 years, with a mean of 60.8 years. Maleto-female ratio was 1:1.5. Pathologies operated on were lumbar spondylosis with canal stenosis and instability 8 patients (32\%), lumbar spondylosis with canal stenosis without instability 6 patients (24\%), canal stenosis 4 patients (16\%), severe cervical spondylosis 3 patients (12\%), spondylolisthesis 2 patients (8\%) and metastatic tumour spread to the spine 2 patients (8\%). Operative procedures carried out were laminectomy with instrumented posterolateral fusion (PLF) 8 (56\%), laminectomies and non-instrumented posterolateral fusion 9 (36\%) and anterior cervical decompression and fusion (ACDF) 3 (12\%). 21 patients had a reduction by 6 or more points on the numeric pain scale (84\%). One patient had cerebrospinal fluid leak which was treated nonoperatively; 2 patients had superficial surgical site infection and one patient was reoperated for persistent radiculopathy and improved thereafter.

\section{CONCLUSION}

Spine surgery is a safe and effective means of treating various spine pathologies with minimal risks and more of these procedures will be employed in view of the increasing number of patients with degenerative spine disease.

\section{KEY WORDS}

Spine, Surgery, Jos, Nigeria.

HOW TO CITE THIS ARTICLE: Bundepuun OM, Olu TF, Idumagbodi A, et al. Spine surgery in Jos, Nigeria- an initial experience. J. Evolution Med. Dent. Sci. 2018;7(26):3049-3052, DOI: 10.14260/jemds/2018/684

\section{BACKGROUND}

Spine pathologies form a large part of case presentations to the orthopaedic and neurosurgeon. These conditions include degenerative spine diseases, trauma to the spine, spine deformities, tumours, spondylolisthesis and spine

'Financial or Other Competing Interest': None.

Submission 04-05-2018, Peer Review 10-06-2018,

Acceptance 16-06-2018, Published 25-06-2018.

Corresponding Author:

Dr. Ode Michael Bundepuun,

Department of Orthopaedics and Trauma,

Jos University Teaching Hospital,

PMB-2076, Jos, Plateau State, Nigeria-930001.

E-mail: odemb2014@gmail.com

DOI: $10.14260 /$ jemds $/ 2018 / 684$ (c) $($ ) $\$$ infections amongst others. A number of these patients can be successfully managed with non-operative treatment modalities, especially the degenerative conditions, but a good number may require surgical intervention for the resolution of their pathologies. Spine surgery procedures are now a mainstay for the treatment of these pathologies and they serve to decompress the neural structures, stabilise the spine and correct deformity.(1-4) There is an increasing ageing population worldwide and a consequent increase in the diseases that affect such a demographic. Degenerative spine diseases which occur with increasing age(5-7) are now a common pathology presenting to the clinician. There is thus a growing requirement for spine procedures, particularly for the degenerative diseases and in some societies there has been a significant increase in the need for spine surgeries for 
degenerative conditions.(7-9) Various surgical treatment options are available and are employed depending on the pathology, the clinical state of the patient, the cost and availability of equipment and the expertise of the surgical team. Some of the employed techniques include hemilaminectomies or total laminectomies, discectomies (open or microscopic), combined with fusion techniques which may be instrumented (e.g. posterior lumbar interbody fusions [PLIF], transforaminal interbody fusions [TLIF], posterolateral fusions $[\mathrm{PLF}]$, anterior cervical decompression and fusions [ACDF]) or non-instrumented fusions using bone graft alone or in combination with hydroxylapatite. ${ }^{(3,10-13)}$ These procedures have been shown to be effective in the treatment of spinal conditions (degenerative, traumatic, infective and in tumours) both of the lumbar and cervical regions. The growing need for spine surgical procedures thus would necessitate an increased requirement for surgeons with such skill sets to meet the demand. Hitherto in Nigeria the availability of spine procedures was limited, but there has been a steadily growing availability of surgeons offering such who are spread across the various regions in the country.

\section{MATERIALS AND METHODS}

This was a case series of retrospectively reviewed data on spine operative procedures done within a two-year period at Daisyland orthopaedic and trauma hospital and Rayfield Medical Services in Jos Nigeria between July 2015 and June 2017. All patients who had spinal surgery procedures in these hospitals within this period were included in the study and their data were recovered from the case notes and database and were reviewed for the indication of spinal surgery, type of procedure, transfusion requirements, postoperative complications and outcome following care. Outcome was assessed by the reduction in pain. The patient had following surgery and this was assessed using the numeric pain rating scale (11 point scale).(14) With 10 as the worst possible pain down to 0 as no pain at all. Reduction to 2 points or less from 10 were considered very good, 3 to 4 good, 5 to 7 fair, 8 and above poor. The data was analysed using the Epi Info statistical software.

\section{RESULTS}

A total of 25 patients had spine surgical procedures within the period. The patient's ages ranged from 35 to 77 years with a mean age range of 60.8 years. A male-to-female ratio of $\mathrm{M}$ : F 1: 1.5. The indications for the procedures were lumbosacral spondylosis with canal stenosis and instability 8 patients (32\%), lumbosacral spondylosis with canal stenosis without instability 6 patients (24\%), spinal canal stenosis 4 patients (16\%), severe cervical spondylosis 3 patients $(12 \%)$, spondylolisthesis 2 patients (8\%), metastatic tumour spread to the lumbar spine 2 patients (8\%) Table 1 . The procedures carried out included laminectomy with instrumented posterolateral fusions (PLF) 13 (52\%), laminectomy with non-instrumented posterolateral fusions 9 (36\%), anterior cervical decompression and fusion (ACDF) 3 (12\%) Table 2. The mean duration of surgery was 210 minutes and the mean transfusion requirement was 2.5 units of blood. Very good outcomes were recorded in 11 patients (44\%), good in 10 patients (40\%), fair in 2 patients $(8 \%)$ and poor in 2 patients $(8 \%)$ Table 3. Complications noted were dural tear (Noticed by CSF leakage) in 1 patient, (Managed non-operatively and treated), superficial surgical site infection in two patients, (Treated with wound dressings and antibiotic therapy) and persistent radiculopathy 4 patients. One of these required reoperation, the other three had subsequent improvement.

\begin{tabular}{|c|c|c|c|}
\hline & Diagnosis & No. & \% \\
\hline 1 & $\begin{array}{c}\text { Lumbosacral spondylosis with canal } \\
\text { stenosis and instability }\end{array}$ & 8 & $32 \%$ \\
\hline 2 & $\begin{array}{c}\text { Lumbosacral spondylosis with canal } \\
\text { stenosis without instability }\end{array}$ & 6 & $24 \%$ \\
\hline 3 & Spinal canal stenosis only & 4 & $16 \%$ \\
\hline 4 & Cervical spondylosis & 3 & $12 \%$ \\
\hline 5 & Spondylolisthesis & 2 & $8 \%$ \\
\hline 6 & Metastasis to the spine & 2 & $8 \%$ \\
\hline \multicolumn{4}{|c|}{ Table 1. Indications for Spine Surgery Procedure } \\
\hline
\end{tabular}

\begin{tabular}{|c|c|c|c|}
\hline & Surgical Procedure & No. & $\mathbf{\%}$ \\
\hline 1 & $\begin{array}{c}\text { Laminectomy with instrumented } \\
\text { posterolateral fusion }\end{array}$ & 13 & $52 \%$ \\
\hline 2 & $\begin{array}{c}\text { Laminectomy with non-instrumented } \\
\text { posterolateral fusion }\end{array}$ & 9 & $36 \%$ \\
\hline 3 & $\begin{array}{c}\text { Anterior cervical decompression and } \\
\text { fusion (ACDF) }\end{array}$ & 3 & $12 \%$ \\
\hline & \multicolumn{3}{|c|}{ Table 2. Operative Procedures } \\
\hline \multicolumn{3}{|c|}{} \\
\hline
\end{tabular}

\begin{tabular}{|c|c|c|c|}
\hline & Pain Reduction Points & No. & Percentage \\
\hline Very good & $\geq 8$ & 11 & $44 \%$ \\
\hline Good & $6-7$ & 10 & $40 \%$ \\
\hline Fair & $3-5$ & 2 & $8 \%$ \\
\hline Poor & $\leq 2$ & 2 & $8 \%$ \\
\hline Total & $\mathbf{2 5}$ & $\mathbf{1 0 0 \%}$ \\
\hline Table 3. Outcome by Pain Assessment (Numeric Pain \\
Scale) \\
\hline
\end{tabular}

\section{DISCUSSION}

We had 25 patients who were operated upon within the said period. The mean age of these patients was 60.8 years in keeping with the fact that most of the conditions treated were degenerative spine conditions, which tend to manifest from about the $5^{\text {th }}$ decade of life. In the study by Hirano et al, they found a mean age of 52.5 years.(15) Yakubi et al had a mean age of 60.0 years,(16) similar to our study. These patients had been treated non-operatively initially without significant improvement. More spine surgery procedures are now being carried out for degenerative conditions presently as noted by Kobayashi and colleagues in their multicentre study(10) and other researchers. $(8,17)$

In this study there was a female predominance M: F 1: 1.5, while in the study by Pasha et al there was a slight male predominance.(18) Ojo et al $^{(19)}$ also had a male preponderance in their study with a male: female ratio of M: F 1.2: 1 .

The commonest indications we found were lumbosacral spondylosis with canal stenosis with or without instability forming $56 \%$ of the indications for which we operated. This was similar to findings made by Aizawa and colleagues.(8) Those with instability formed $32 \%$ and those without instability making up $24 \%$ of the total cases. Spondylolisthesis and metastatic tumour spread were the least common indications, $8 \%$ each. The procedures carried out were decompression with instrumented posterolateral fusions 52\%, decompression with non-instrumented posterolateral fusion $36 \%$, anterior cervical decompression 
and fusion $12 \%$. The mean duration of surgery was 210 minutes. The instrumented procedures lasting longer than the non-instrumented procedures.

Pain was assessed as an outcome measure using the numeric pain scale. $44 \%$ of the patients had a reduction of 8 or more points, $40 \%$ of the patients had a reduction of 6 to 7 points. $8 \%$ had a reduction of 2 or less points in the reduction of pain. Thus, $84 \%$ of the patients had a reduction of more than six points in their assessment of pain severity. The numeric pain rating scale is widely applied in assessing outcome measures in spine surgery along with other outcome measuring tools.(14, 20-22) From the findings in our study, most $(84 \%)$ of our patients had 6 or more point reduction in pain following surgery indicating a beneficial effect of the surgical procedures.

The complications we encountered (surgical site infections, persistent radiculopathies and dural tear) were similar to the postoperative complications noted by Shimizu et al.(23) There was a superficial surgical site infection rate of $8 \%$ in our study as compared to $4.8 \%$ obtained in other studies.(19) Kim et al had a reoperation rate of $7.4 \%$ at 1 year postoperatively.(24) We had to take one patient back for reoperation due to persistent radiculopathy on the $8^{\text {th }}$ postoperative day. The intraoperative finding showed inadequate decompression at the initial surgery. Reoperation rate was $4 \%$ in our study. In the study by Shimizu and colleagues,(23) they had a reoperation rate of $1.6 \%$ and the leading reason for reoperation was motor paralysis due to epidural haematoma. Wadhwa et al in a large multicentre study had a reoperation rate of $2 \% .(25)$

\section{CONCLUSION}

Spine surgery procedures are safe and effective in the treatment of spine pathologies. The increase in ageing populations worldwide will mean an increase in the cases of degenerative spine pathologies that may require surgical intervention with all the other pathologies requiring spine surgery. There will thus be an increase in the requirement for these procedures to improve the quality of life in these patients.

\section{REFERENCES}

[1] Ojo OA, Poluyi EO, Owolabi BS, et al. Surgical decompression for traumatic spinal cord injury in a tertiary center. Nigerian Journal of Clinical Practice 2017;20(11):1455-60.

[2] Lee JK, Jung SK, Lee YS, et al. Analysis of the fusion and graft resorption rates, as measured by computed tomography, 1 year after posterior cervical fusion using a cervical pedicle screw. World Neurosurgery 2017;99:171-8.

[3] Kepler CK, Vaccaro AR, Hilibrand AS, et al. National trends in the use of fusion techniques to treat degenerative spondylolisthesis. Spine (Phila Pa 1976) 2014;39(19):1584-9.

[4] Ailon T, Sure DR, Smith JS, et al. Surgical considerations for major deformity correction spine surgery. Best Practice \& Research Clinical Anaesthesiology 2016;30(1):3-11.
[5] Tsujimoto R, Abe Y, Arima K, et al. Prevalence of lumbar spondylosis and its association with low back pain among community-dwelling Japanese women. BMC Musculoskeletal Disorders 2016;17(1):493.

[6] Teraguchi M, Yoshimura N, Hashizume $H$, et al. Prevalence and distribution of intervertebral disc degeneration over the entire spine in a populationbased cohort: the Wakayama Spine Study. Osteoarthritis and Cartilage 2014;22(1):104-10.

[7] O'Lynnger TM, Zuckerman SL, Morone PJ, et al. Trends for spine surgery for the elderly: implications for access to healthcare in North America. Neurosurgery 2015;77 Suppl 4:S136-41.

[8] Aizawa T, Kokubun S, Ozawa $\mathrm{H}$, et al. Increasing incidence of degenerative spinal diseases in Japan during 25 years: the registration system of spinal surgery in Tohoku University Spine Society. The Tohoku Journal of Experimental Medicine 2016;238(2):153-63.

[9] Schulz C, Kunz U, Mauer UM, et al. Spine surgery in a combat support hospital. Der Orthopade 2016;45(4):341-8.

[10] Kobayashi K, Ando K, Nishida Y, et al. Epidemiological trends in spine surgery over 10 years in a multicenter database. European Spine Journal: Official Publication of The European Spine Society, The European Spinal Deformity Society, and The European Section of the Cervical Spine Research Society 2018: p. 1-6.

[11] Tsuji T, Watanabe K, Hosogane N, et al. Risk factors of radiological adjacent disc degeneration with lumbar interbody fusion for degenerative spondylolisthesis. Journal of Orthopaedic Science: Official Journal of The Japanese Orthopaedic Association 2016;21(2):133-7.

[12] Lin JH, Chien LN, Tsai WL, et al. Reoperation rates of anterior cervical discectomy and fusion versus posterior laminoplasty for multilevel cervical degenerative diseases: a population-based cohort study in Taiwan. The Spine Journal: Official Journal of The North American Spine Society 2016;16(12):142836.

[13] Norton RP, Bianco K, Klifto C, et al. Degenerative spondylolisthesis: an analysis of the nationwide inpatient sample database. Spine 2015;40(15):121927.

[14] Chan AK, Bisson EF, Bydon M, et al. Women fare best following surgery for degenerative lumbar spondylolisthesis: a comparison of the most and least satisfied patients utilizing data from the Quality Outcomes Database. Neurosurgical Focus 2018;44(1):E3.

[15] Hirano K, Imagama S, Matsuyama Y, et al. Surgically treated cases of lumbar spondylolysis and isthmic spondylolisthesis: a multicenter study. Journal of Spinal Disorders \& Techniques 2015;28(5):193-7.

[16] Yabuki S, Fukumori N, Takegami M, et al. Prevalence of lumbar spinal stenosis, using the diagnostic support tool and correlated factors in Japan: a populationbased study. Journal of Orthopaedic Science: Official Journal of the Japanese Orthopaedic Association 2013;18(6):893-900. 
[17] Yamato Y, Matsuyama Y, Hasegawa K, et al. A Japanese nationwide multicenter survey on perioperative complications of corrective fusion for elderly patients with adult spinal deformity. Journal of Orthopaedic Science: Official Journal of the Japanese Orthopaedic Association 2017;22(2):237-42.

[18] Pasha IF, Qureshi MA, Haider IZ, et al. Surgical treatment in lumbar spondylolisthesis: experience with 45 patients. Journal of Ayub Medical College Abbottabad: JAMC 2012;24(1):75-8.

[19] Ojo OA, Owolabi BS, Oseni AW, et al. Surgical site infection in posterior spine surgery. Nigerian Journal of Clinical Practice 2016;19(6):821-6.

[20] Kim EJ, Chotai S, Wick JB, et al. Patient reported outcomes and costs associated with revision surgery for degenerative cervical spine diseases. Spine 2018;43(7):E423-E9.

[21] Ailon T, Smith JS, Shaffrey CI, et al. Outcomes of operative treatment for adult cervical deformity: a prospective multicenter assessment with 1-year follow-up. Neurosurgery 2017.
[22] Dorow M, Lobner M, Stein J, et al. The course of pain intensity in patients undergoing herniated disc surgery: a 5-year longitudinal observational study. PLoS One 2016;11(5):e0156647.

[23] Shimizu T, Fujibayashi S, Takemoto M, et al. A multicenter study of reoperations within 30 days of spine surgery. European Spine Journal: Official Publication of The European Spine Society, The European Spinal Deformity Society, and The European Section of the Cervical Spine Research Society 2016;25(3):828-35.

[24] Kim CH, Chung CK, Park CS, et al. Reoperation rate after surgery for lumbar herniated intervertebral disc disease: nationwide cohort study. Spine 2013;38(7):581-90.

[25] Wadhwa RK, Ohya J, Vogel TD, et al. Risk factors for 30-day reoperation and 3-month readmission: analysis from the Quality and Outcomes Database lumbar spine registry. Journal of Neurosurgery Spine 2017;27(2):131-6. 